\title{
DOSSIÊ: RESOLUÇÃO DE PROBLEMAS NA EDUCAÇÃO MATEMÁTICA
}

A realização de eventos sobre a resolução de problemas é importante para a divulgação das experiências e pesquisas com esta temática. Assim, organizar e realizar o evento intitulado I Simpósio de Resolução de Problemas na Educação Matemática (I SiRPEM) foi uma iniciativa do Grupo de Estudos em Resolução de Problemas na Educação Matemática (GERPEM), liderado pelo professor Dr. Marcelo Carlos de Proença da Universidade Estadual de Maringá, Maringá, Paraná. O evento foi realizado no formato on-line e contou com duas palestras (abertura e encerramento), duas mesas redondas e oito sessões de apresentação de trabalhos. Os trabalhos versaram sobre a temática da resolução de problemas e foram enviados nas modalidades comunicação científica e relato de experiência. Em parceria com a REMAT: Revista Eletrônica da Matemática (e-ISSN: 2447-2689, DOI: 10.35819), alguns trabalhos do tipo pesquisa empírica e pesquisa bibliográfica foram selecionados para comporem este Dossiê que envolve a resolução de problemas na Educação Matemática.

A Comissão Organizadora do I SiRPEM gerenciou o processo de avaliação por pares das submissões recebidas, contando com 26 pareceristas. Ao todo foram 24 submissões de trabalhos, dos quais 22 foram aceitos para apresentação e sete foram indicados para publicação na REMAT.

Os artigos recebidos pela REMAT passaram pela avaliação do Corpo de Editores da Seção Educação Matemática e pela revisão linguística de seus Revisores de Texto.

Os seguintes trabalhos compõem este Dossiê:

1. Resolução de problemas em Educação Matemática e o desenvolvimento de habilidades de pensamento de ordem superior - Gilberto Vieira, Norma Suely Gomes Allevato.

2. Análise das dificuldades de futuros pedagogos no processo de resolução de problemas geométricos - Érika Janine Maia-Afonso, Marcelo Carlos de Proença.

3. A docência nos anos iniciais através da Resolução de Problemas: da formação de professores à implementação de uma aula sobre frações unitárias - Fábio Vieira Abrão, Norma Suely Gomes Allevato.

4. A Proposição e Resolução de Problemas na aprendizagem de Matemática: possibilidades para o Ensino Superior - Leonardo Cristiano Gieseler, Bruno Schneider, Janaína Poffo Possamai, Norma Suely Gomes Allevato.

\footnotetext{
${ }^{1}$ Edição Especial - Dossiê: Resolução de Problemas na Educação Matemática - Artigos apresentados no I Simpósio de Resolução de Problemas na Educação Matemática (I SiRPEM), da Universidade Estadual de Maringá, Maringá, Paraná, realizado nos dias 29 e 30 de julho de 2021.
} 
5. A Resolução de Problemas no Ensino Médio: um mapeamento realizado nos anos 2016 a 2020 - Vilmar Ibanor Bertotti Junior, Tayana Cruz de Souza, Janaína Poffo Possamai.

6. Um panorama da resolução de problemas na visão das pesquisadoras brasileiras Onuchic e Allevato - Manoel dos Santos Costa.

7. Ensino-aprendizagem de Matemática via Resolução de Problemas: análise do processo de resolução de problemas de licenciandos em formação inicial - Luiz Otavio Rodrigues Mendes, Marcelo Carlos de Proença, Ana Lucia Pereira, João Alessandro da Luz.

Agradecemos a todos os que participaram deste processo, desde a idealização do I SiRPEM até a publicação deste Dossiê, possibilitando ricas discussões sobre a resolução de problemas na Educação Matemática.

Desejamos uma ótima leitura!

Caxias do Sul, 30 de dezembro de 2021.

Dra. Greice da Silva Lorenzzetti Andreis - Editora-chefe da REMAT Dr. Marcelo Carlos de Proença - Coordenador Geral da Comissão Organizadora do I Simpósio de Resolução de Problemas na Educação Matemática 